\title{
A Study on the Level of Comprehension and Satisfaction With Distance Learning During the COVID-19 Pandemic
}

\author{
Hiroko Kanoh ${ }^{1}$ \\ ${ }^{1}$ Institute of Arts and Sciences, National University Corporation Yamagata University, Yamagata, Japan \\ Correspondence: Hiroko Kanoh, Associate Professor, Institute of Arts and Sciences, National University Corporation \\ Yamagata University, Yamagata, Japan. Tel: 81-23-628-4689. E-mail: kanoh@cc.yamagata-u.ac.jp
}

Received: August 31, 2021

Accepted: September 20, 2021

Online Published: September 22, 2021

doi:10.5430/irhe.v6n3p29

URL: https://doi.org/10.5430/irhe.v6n3p29

The research is financed by the Takahashi Industrial and Economic Research Foundation.

\begin{abstract}
The purpose of this paper is to clarify how students perceive changes in the educational environment, such as distance learning. A survey was conducted by creating questions that were narrowed down into specific methods, such as categorizing remote teaching methods as text-based, on-demand, or interactive, and sub-dividing the on-demand type into slides with sound and on-demand via video recording. As a result, the most common type of class was text-based. The one with the highest level of comprehension was the interactive type, while the on-demand type was found to have the highest level of satisfaction. It was also found that many students believe that Distance learning would continue for some time, with only a minority being willing to take classes in the classroom despite concerns about infection. While many students felt that distance learning was good for them, such as "I don't need to commute to school" and "I can rewatch videos," some concerns included "I can't make new friends" and "It's hard to communicate with others." Since students who felt lonely with Distance learning fell into two extremes, they were divided into a high loneliness group and a low loneliness group for comparison. As a result, it was found that students with high loneliness did not enjoy Distance learning and were unable to make new friends, while students with low loneliness seemed to enjoy Distance learning and were able to make new friends even when online.
\end{abstract}

Keywords: COVID-19 pandemic, university students, distance learning, text-based, on-demand, interactive

\section{Introduction}

\subsection{Introduce the Problem}

With the COVID-19 pandemic, many universities were forced to adopt Distance learning which became quickly widespread. Distance learning was conducted all over the world. What is the level of attitudes of students towards e-learning during the COVID-19 pandemic? In a case study of Cyprus, there is a positive relationship between digital citizenship behaviors and e-learning attitudes. In addition, it has been observed that the negative anxiety of students due to the pandemic is reflected in their e-learning processes. However, overall results show that digital citizenship behavior digital learning process could be a positive response to COVID-19 closure period(Akcil \& Bastas, 2021).

In a case study of Indnesia, higher number of first-year students preferred Distance learning compared to their seniors. Despite some challenges, dental students could adapt to the new learning methods of full DL and the majorities agreed blended learning that combined classroom and distance learning can be implemented henceforth. This current COVID-19 pandemic, changes not only the utilization of technology in education but the pedagogy strategies in the future(Amir et al., 2020).

In a case study of Bangladesh, revealed that m-learning is very helpful to recover the study gap during this COVID-19 pandemic time and the findings of this study will help the education policymaker as well as the educational institutions to incorporate mobile learning technology for the whole system where social media may enhance the process of teaching and learning(Biswas, Roy, \& Roy, 2020).

In a case study of Malaysia, disclosed various obstacles they en-countered when they used IT platform applications for online learning. These obstacles include (a) work and information overload received from instructors, (b) 
inadaptability and unfamiliarity of the new online learning environment, and (c) personal health challenges related to stress and anxi-ety(Al-Kumaim et al., 2021).

In a case study of Bulgaria, available free access for Google Classroom and Meet, MS Teams, Office 365 and OneDrive for Bulgarian students, teachers, and professors. But most of the students $(88.1 \%)$ had no previous experience in e-learning, as they had not used digital learning platforms (LMS) prior to the outbreak of COVID-19. The students rely on different platforms to receive study materials during the lockdown period. They use Google Meet to attend e-classes (85\%), followed by Zoom (6.8\%), YouTube (5.3\%) and Microsoft Team (3\%). The lecturers rapidly mastered not only a variety of platforms for digital teaching and learning, but also for students' assessment: Moodle (57.9\%), Google Classroom (29.3\%) and Google form (9.8\%). There are some problems in distance learning, the sentiment analysis of students' opinions shows that the majority $(68 \%)$ demonstrates a positive attitude to distance learning as a temporary measure for coping with the COVID-19 pandemic(Ilieva, Yankova, Klisarova-Belcheva, \& Ivanova, 2021).

According to a survey by the Ministry of Education, Culture, Sports, Science and Technology in Japan, 1066 universities (99.7\%) were offering classes as of June 1, 2020. For national universities in Japan, none were offering only physical classes. In total, including public, private, and technical colleges, 322 schools $(30.2 \%)$ adopted both physical and Distance learning, while 641 schools (60.1\%) adopted Distance learning. Only 103 schools (9.7\%) offered solely psychical classes, and $90 \%$ of higher education institutions have started to conduct remote classes (Ministry of Education, Culture, Sports, Science and Technology, 2020).

In the beginning, concerns were raised about the ownership of PCs and internet connection, but with more than $90 \%$ of the students owning both a PC and internet connection, there were no psychical problems in terms of the environment (Kanoh, 2020).

On the other hand, even though classes were suddenly switched to remote, most of the teachers were only prepared for physical learning, and they had to prepare for Distance learning by cutting down their own private life, research time, and sleep time. Therefore, teaching methods were not unified with various kinds being conducted.

The methods of Distance learning conducted can be classified into the following three types:

1) Text-based: Using books, mailing materials, and distributing materials via an LMS

2) On-demand: Submitting assignments after watching recorded videos

3) Interactive: Real-time Distance learning using interactive communication tools such as Zoom and Meet

All three of them were conducted in different ways from the teaching method described in the syllabus the previous year. University faculty members were forced to respond urgently, with things conducted through trial and error.

\subsection{Purpose of Research}

Therefore, the purpose of this paper is to clarify how students perceived Distance learning and other changes that happened suddenly due to the state of emergency with COVID-19. Even with Distance learning, some classes had just handouts, while others had interactive lessons with on-demand videos, group discussions using breakout rooms, the KJ method using brainstorming tools, and more using various tools. By analyzing the level of comprehension and satisfaction with each teaching method and how they perceived future teaching methods and more, we will obtain suggestions for a more desirable Distance learning.

\section{Method}

A questionnaire survey was conducted among 239 university students from 6 universities, with a response period from July 15th to August 31st, 2020. Due to the impact of COVID-19, the end of the first semester was different depending on the university. As we asked for responses at the end of classes from the previous semester, the response period lasted one and a half months. As for the faculties, we classified the faculty of science and engineering as science-related, the faculty of humanities and law as liberal arts, and the rest as others.

For survey items related to teaching methods, we asked for responses on how many teaching methods were used in classes taken by the students during the six months. Furthermore, students were asked to rate their level and comprehension satisfaction of the class using a six-point scale from "1 low" to "6 high" for each teaching method. For attitudes toward distance learning, students were asked to rate based on a 6-point scale from "1-not applicable" to "6- applicable". IBM SPSS Statistics, Version 24 was used as the statistical analysis software, and a description field is also provided in addition to the multiple-choice items. 


\section{Results}

\subsection{Teaching Method}

The number of classes in which each teaching method was used per student is as shown (Table1). Since not all students have experienced each teaching method, the number of people may vary for each method. From the table, we can see that 353 people have experienced text-based classes via printed materials and books with an average of 7.59 , which was the most common format used.

The next most common teaching method was interactive, experienced by 352 people and used in an average of 4 classes. Classes that impose report assignments were experienced by 342 people and were used in an average of 6 classes, classes with multiple-choice tests were experienced by 322 students in an average of 4 classes, and classes using on-demand teaching materials via PowerPoint slides with sound were experienced by 292 people and were used in an average of 4 classes.

While the number of people who had taken classes by submitting assignments using LMS was 237, this format was used in an average of 9 or more classes. Since LMSs are usually required to be contracted by universities, it can be inferred that those universities that had contracts were actively using it, while those that did not have contracts were not.

On the other hand, only 46 students have experience using brainstorming tools. Classroom classes and practical exams were also held in some parts, with 99 people taking practical exams and 62 people taking classroom lessons.

Table 1. Teaching method

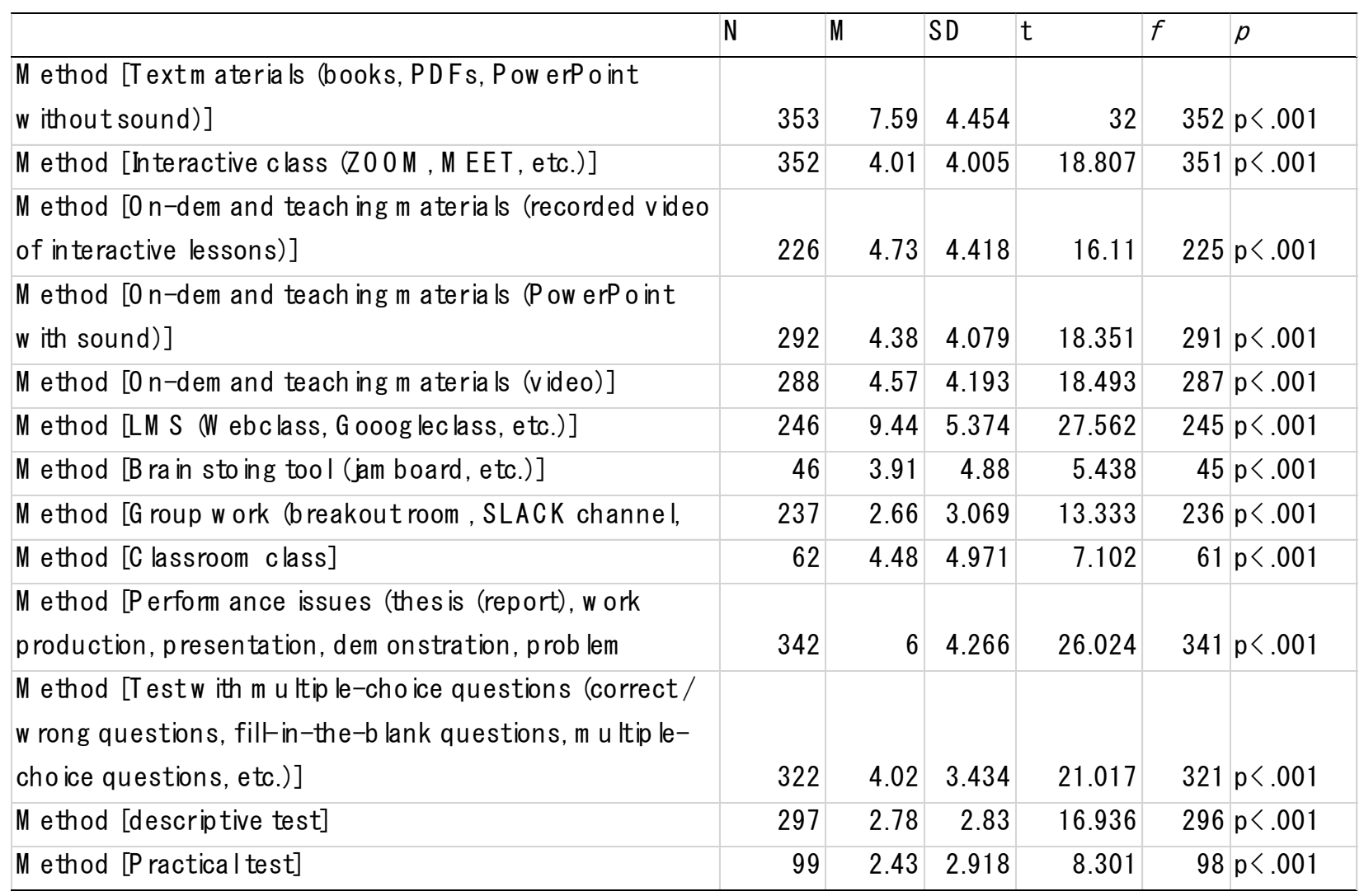

\subsection{Level of Comprehension and Satisfaction With Classes}

As shown in the Table 2, it was found that the level of comprehension of interactive classes using Zoom, Meet, etc. was 4.37 , the highest for comprehension. The on-demand teaching materials by video was 4.32 , the second highest for comprehension. In contrast, while only 46 students have used brainstorming tools, 98 respondents suggested that they chose a low level of understanding because they had no experience using it, resulting in a lower average level of understanding. 
Table 2. Level of comprehension with classes

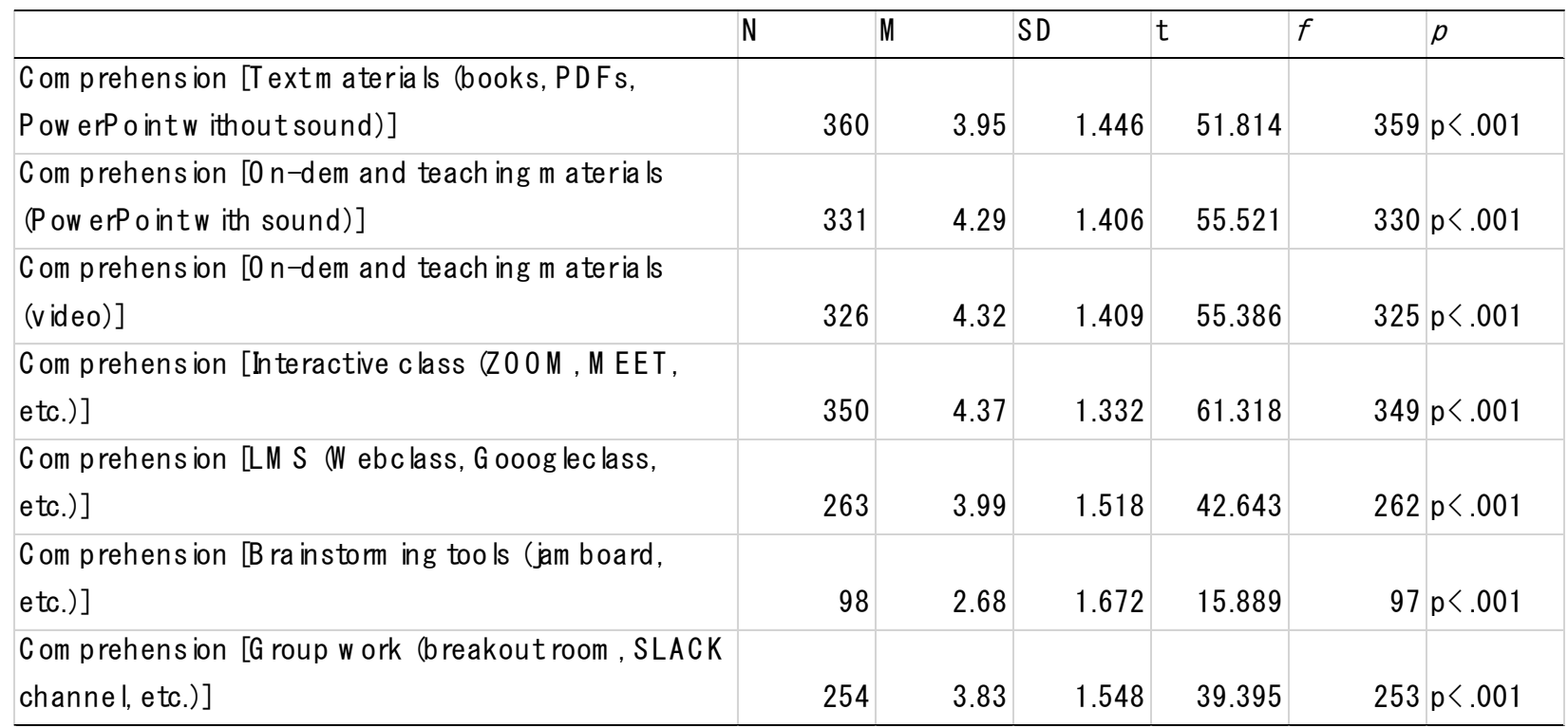

Table 3 shows Level of Satisfaction with Classes. From the Table 3, the level of satisfaction of on-demand teaching materials by video was the highest at 4.33 , followed by on-demand via PowerPoint slides with sound at 4.30 and interactive at 4.26 .

Table 3. Level of satisfaction with classes

\begin{tabular}{|c|c|c|c|c|c|c|}
\hline & $\mathrm{N}$ & M & SD & $t$ & $f$ & $p$ \\
\hline $\begin{array}{l}\text { Satisfaction [T extm ateria ls (books, PDFs, } \\
\text { P ow erP o intw ithout sound)] }\end{array}$ & 359 & 4.04 & 1.478 & 51.803 & 358 & $p<.001$ \\
\hline $\begin{array}{l}\text { Satisfaction }[0 n-d e m \text { and teach ing } m \text { aterials } \\
(P \text { ow erP o int } w \text { ith sound })]\end{array}$ & 329 & 4.3 & 1.399 & 55.817 & 328 & $p<.001$ \\
\hline $\begin{array}{l}\text { Satisfaction }[0 n-d e m \text { and teach ing } m \text { aterials } \\
(v \text { ideo })]\end{array}$ & 329 & 4.33 & 1.378 & 56.985 & 328 & $p<.001$ \\
\hline $\begin{array}{l}\text { Satisfaction [Interactive class }(\mathrm{Z} 00 \mathrm{M}, \mathrm{MEET} \text {, } \\
\text { etc.)] }\end{array}$ & 350 & 4.26 & 1.366 & 58.338 & 349 & $p<.001$ \\
\hline $\begin{array}{l}\text { Satisfaction [LM S (W ebclass, Gooog leclass, } \\
\text { etc.)] }\end{array}$ & 259 & 4.1 & 1.52 & 43.451 & 258 & $p<.001$ \\
\hline $\begin{array}{l}\text { Satisfaction [B ra instorm ing too ls (jam board, } \\
\text { etc.)] }\end{array}$ & 99 & 2.81 & 1.608 & 17.377 & 98 & $p<.001$ \\
\hline $\begin{array}{l}\text { Satisfaction [G roup w ork (b reakout room, } \\
\text { SLACK channel, etc.)] }\end{array}$ & 250 & 3.86 & 1.534 & 39.781 & 249 & $p<.001$ \\
\hline
\end{tabular}

\subsection{Attitudes Toward Distance Learning}

Table4 show Attitudes Toward Distance Learning. From the Table 4, "I think distance learning will continue for a while" was rated 4.71, with more than half of the students predicting that it would be as so for a while. "I'm not tied to a set study time" was rated 4.13, with more than half of the students feeling they are not constricted by time.

Additionally, "I want to take classes in the classroom even with the pandemic" was rated 2.8, and "We should continue distance learning as long as the pandemic persists" was rated 4.28, indicating that only a minority of 
students would want to take classes in a classroom even if they were worried about infection.

"I like distance learning" was rated 3.69 and "I dislike distance learning" was rated 3.07, indicating that more students prefer distance learning.

"Distance learning lets me concentrate on my studies better" was rated 3.07, indicating that there was no bias toward either being able to focus or not being able to because it was online. When asked verbally, some students said that they could concentrate better online as they could take classes in a quiet environment in their room without being influenced by their surroundings. On the other hand, when taking remote classes at home, some students said that they tend to reach for sweets or juice or cannot concentrate due to lack of time management.

With "I feel helpless" at 3.2, "I can't comprehend the lessons with remote earning" at 3.38, and "I can't continue my studies due to distance learning" at 3.35, it was found that a number of students cannot comprehend the lessons or have difficulty in continuing their studies.

While "I think it is appropriate to give credits for remote classes" was rated 3.78 with more than half of the students holding this opinion, there were a number of students who thought otherwise.

Table 4. Attitudes toward distance learning

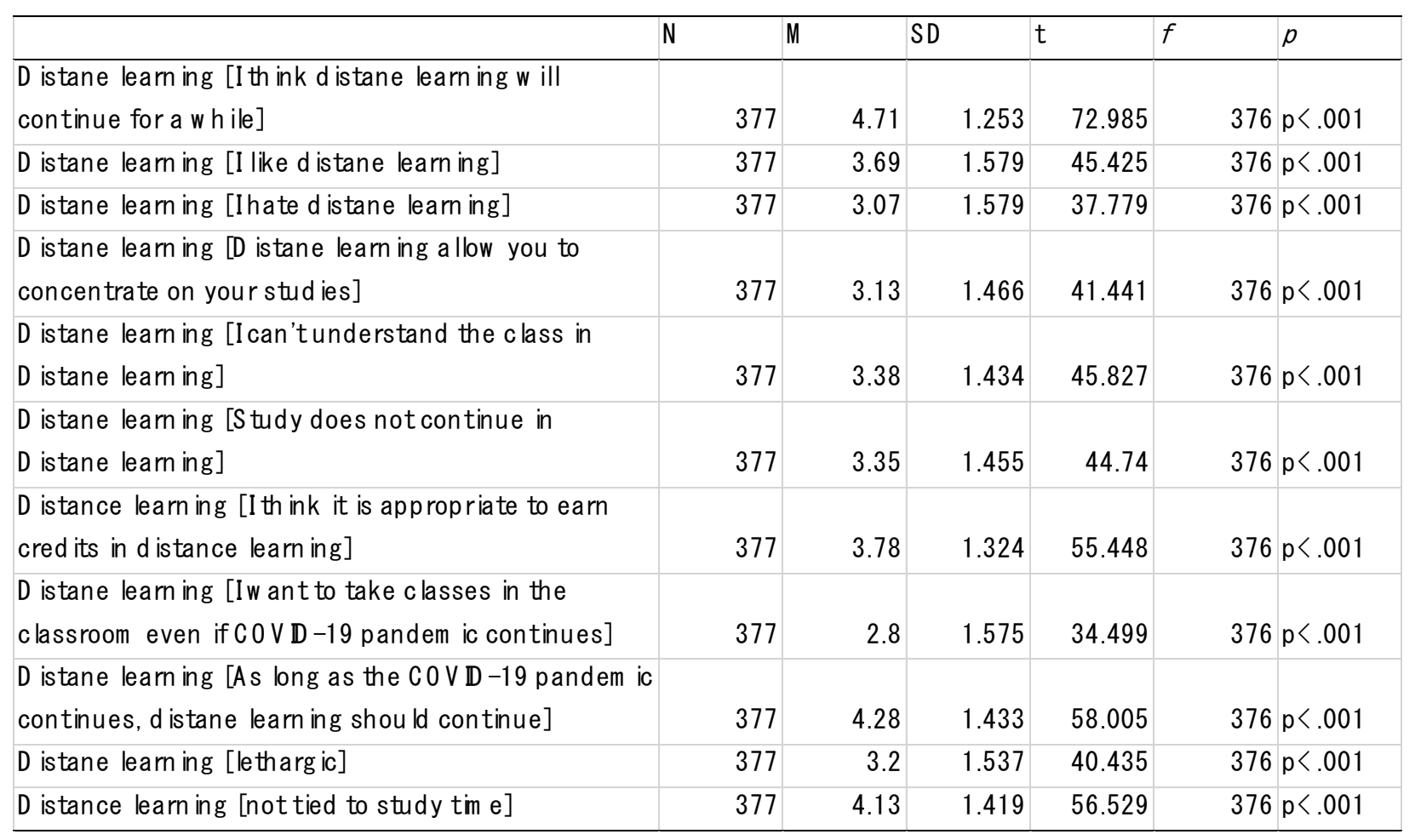

\subsection{Pros and Cons}

Table 5 shows pros and cons of distans learning. More than half of the students were found to perceive the pros of distance learning as "I don't need to commute", "I'm not constrained by time", "I don't need to get dressed", and "I can rewatch videos". While some students described distance learning as "enjoyable", the number of responses was limited.

As for some of the cons, student responded "I can't make new friends," "I feel physical fatigue (e.g., tired eyes)," "It's hard to communicate with others," "It's hard to ask for advice," "I can't do experiments," "I want to do club activities," and "It's hard to use the library.

While limited, they were a number of responses for "I don't know how to use the online tools," "The sound and video are choppy," and "I'm worried about my internet connection." Few students responded "I felt anxious (for reason other above)" about distance learning, indicating that most students were able to take remote classes if necessary. 
For "I feel lonely", the average was 3.37, with 114 students giving a rating of 5 or 6.

Table 5. Pros and cons

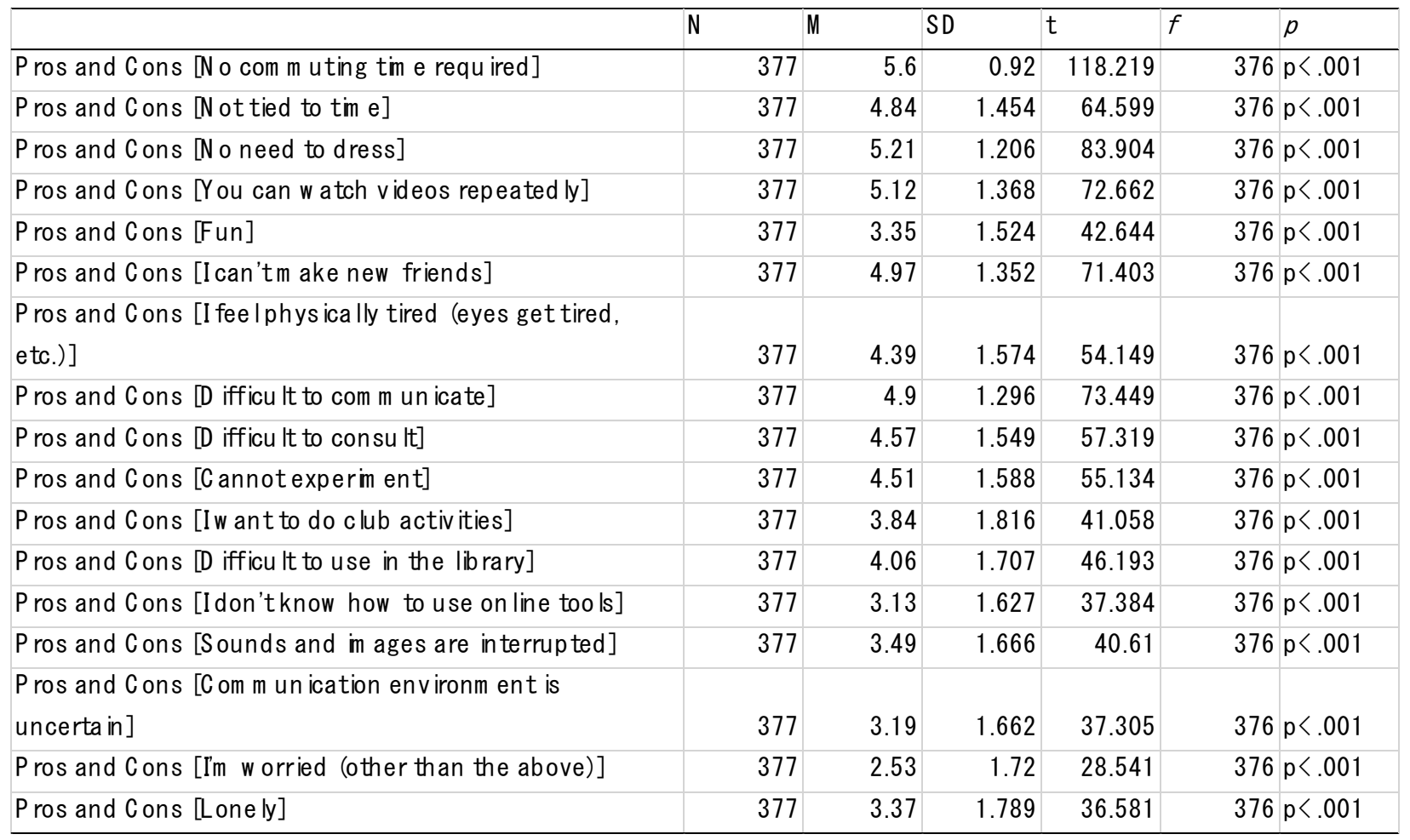

Hence, we categorized students into a low loneliness group and a high loneliness group, and investigated the relationship between high/low loneliness and other items via analysis of variance (Table 6). As a result, the loneliness score of the low group was 3.81 and that of the high group was 2.83 for item "enjoyable" for distance learning. In other words, students who strongly felt loneliness in a life of distance learning did not enjoy it, while students who did not feel loneliness found it enjoyable.

It was also found that students with a high loneliness showed difficulty in making new friends, while students with a low loneliness did not find it difficult to make new friends even in a distance learning setting.

\section{Discussion}

The purpose of this paper is to clarify how students perceive changes in the educational environment, such as distance learning. A survey was conducted by creating questions that were narrowed down into specific methods, such as categorizing remote teaching methods as text-based, on-demand, or interactive, and sub-dividing the on-demand type into slides with sound and on-demand via video recording.

As a result, the most common type of class was text-based. The one with the highest level of comprehension was the interactive type, while the on-demand type was found to have the highest level of satisfaction.

It was also found that many students believe that distance learning would continue for some time, with only a minority being willing to take classes in the classroom despite concerns about infection. While many students felt that distance learning was good for them, such as "I don't need to commute to school" and "I can rewatch videos," some concerns included "I can't make new friends" and "It's hard to communicate with others." Since students who felt lonely with distance learning fell into two extremes, they were divided into a high loneliness group and a low loneliness group for comparison. As a result, it was found that students with high loneliness did not enjoy distance learning and were unable to make new friends, while students with low loneliness seemed to enjoy distance learning and were able to make new friends even when online. 
Table 6. Loneliness $\times$ pros and cons

\begin{tabular}{|c|c|c|c|c|c|c|}
\hline & Lone liness & $\mathrm{N}$ & M & SD & $F$ & $p$ \\
\hline \multirow{3}{*}{ Pros and Cons [No com $\mathrm{m}$ uting tim e required] } & Low & 198 & 5.64 & 0.865 & \multicolumn{2}{|c|}{0.76 N.S. } \\
\hline & $h$ igh & 179 & 5.56 & 0.978 & & \\
\hline & total & 377 & 5.6 & 0.92 & & \\
\hline \multirow{3}{*}{ Pros and $\mathrm{C}$ ons $[\mathrm{N}$ ot tied to tim $\mathrm{e}]$} & Low & 198 & 5.06 & 1.277 & 9.988 & $p<.01$ \\
\hline & $\mathrm{h}$ igh & 179 & 4.59 & 1.596 & & \\
\hline & tota I & 377 & 4.84 & 1.454 & & \\
\hline \multirow{3}{*}{ Pros and Cons [No need to dress] } & Low & 198 & 5.39 & 1.054 & 9.142 & $p<.01$ \\
\hline & $h$ igh & 179 & 5.02 & 1.33 & & \\
\hline & tota I & 377 & 5.21 & 1.206 & & \\
\hline \multirow{3}{*}{ Pros and Cons [You can w atch videos repeated ly] } & Low & 198 & 5.35 & 1.186 & 12.042 & $p<.01$ \\
\hline & $h$ igh & 179 & 4.87 & 1.508 & & \\
\hline & tota I & 377 & 5.12 & 1.368 & & \\
\hline \multirow{3}{*}{ Pros and Cons [Fun] } & Low & 198 & 3.81 & 1.425 & 43.302 & $p<.001$ \\
\hline & $h$ igh & 179 & 2.83 & 1.467 & & \\
\hline & tota I & 377 & 3.35 & 1.524 & & \\
\hline \multirow{3}{*}{ Pros and Cons [I can'tm ake new friends] } & Low & 198 & 4.58 & 1.474 & 38.676 & $p<.001$ \\
\hline & $h$ igh & 179 & 5.41 & 1.047 & & \\
\hline & tota I & 377 & 4.97 & 1.352 & & \\
\hline \multirow{3}{*}{$\begin{array}{l}\text { P ros and Cons [I fee I physically tired (eyes get tired, } \\
\text { etc.)] }\end{array}$} & Low & 198 & 3.89 & 1.605 & 47.469 & $p<.001$ \\
\hline & $h$ igh & 179 & 4.94 & 1.34 & & \\
\hline & tota I & 377 & 4.39 & 1.574 & & \\
\hline \multirow{3}{*}{$P$ ros and $C$ ons [D ifficu lt to com $m$ un icate $]$} & Low & 198 & 4.42 & 1.404 & 68.196 & $p<.001$ \\
\hline & $h$ igh & 179 & 5.44 & 0.906 & & \\
\hline & tota I & 377 & 4.9 & 1.296 & & \\
\hline \multirow{3}{*}{ Pros and Cons [D ifficu lt to consult] } & Low & 198 & 3.92 & 1.62 & 92.313 & $p<.001$ \\
\hline & $h$ igh & 179 & 5.3 & 1.079 & & \\
\hline & total & 377 & 4.57 & 1.549 & & \\
\hline \multirow{3}{*}{ Pros and Cons [C annotexperim ent] } & Low & 198 & 3.94 & 1.653 & 61.205 & $p<.001$ \\
\hline & $\mathrm{h}$ igh & 179 & 5.13 & 1.247 & & \\
\hline & tota I & 377 & 4.51 & 1.588 & & \\
\hline \multirow{3}{*}{ Pros and Cons [Iw ant to do club activities] } & Low & 198 & 3.35 & 1.796 & 32.535 & $p<.001$ \\
\hline & $\mathrm{h}$ igh & 179 & 4.38 & 1.686 & & \\
\hline & tota I & 377 & 3.84 & 1.816 & & \\
\hline \multirow{3}{*}{ Pros and Cons [D ifficu lt to use in the lib rary] } & Low & 198 & 3.47 & 1.648 & 57.569 & $p<.001$ \\
\hline & $\mathrm{h}$ igh & 179 & 4.72 & 1.526 & & \\
\hline & total & 377 & 4.06 & 1.707 & & \\
\hline \multirow{3}{*}{ Pros and Cons [Idon't know how to use on line tools] } & Low & 198 & 2.6 & 1.466 & 50.365 & $p<.001$ \\
\hline & $\mathrm{h}$ igh & 179 & 3.72 & 1.597 & & \\
\hline & tota I & 377 & 3.13 & 1.627 & & \\
\hline \multirow{3}{*}{ Pros and Cons [Sounds and im ages are interrupted] } & Low & 198 & 2.99 & 1.607 & 39.856 & $p<.001$ \\
\hline & $h$ igh & 179 & 4.03 & 1.563 & & \\
\hline & tota l & 377 & 3.49 & 1.666 & & \\
\hline \multirow{3}{*}{$\begin{array}{l}P \text { ros and } C \text { ons [Com } m \text { un ication environm ent is } \\
\text { uncerta in ] }\end{array}$} & Low & 198 & 2.78 & 1.552 & 27.974 & $p<.001$ \\
\hline & $h$ igh & 179 & 3.65 & 1.663 & & \\
\hline & tota I & 377 & 3.19 & 1.662 & & \\
\hline \multirow{3}{*}{ Pros and Cons [Im worried (other than the above)] } & Low & 198 & 1.94 & 1.295 & 54.872 & $p<.001$ \\
\hline & $h$ igh & 179 & 3.17 & 1.896 & & \\
\hline & tota I & 377 & 2.53 & 1.72 & & \\
\hline
\end{tabular}


In the description section for the pros and cons, it was mentioned, "The pro is that you can discuss with your peer during breakout sessions in Zoom". In my class, I had a Zoom breakout session at the end of the class about every hour. Since the members of the class changed each time, some students made a lot of friends, but some kept quiet and did not participate in discussions. One of the students who actively participated in the discussions every hour told me, "I made friends with a person whose voice I had only hear in class when I met him at a driving school for the first time.

They seemed to be enjoying their university life in their own way, making new friends every week through breakout sessions, meeting each other in real life at driving schools, etc., and hanging out with these new-met friends later on. There were also students enjoying their online student life by gathering information about clubs and student life from their seniors through social media. While some student wrote "I don't have to meet people" as a pro, others who had been a member of an athletic club in high school but was not good at making friends online had mental breakdowns and started seeking psychotherapy under the recommendation of the parents.

Besides from pros including "I can relax and concentrate just on the content (without distractions such as the gaze of others and noises)," "I can adjust the environment to my liking and my back doesn't hurt (the chairs are adequately soft and I can move, stand and sit)," and "I can easily go to the washroom," students pointed out some cons: "I can't prepare for teaching practice," "I can't do practical subjects," "I can't do production," and "There are too many class assignments.

While distance learning has spread rapidly this time due to the pandemic, attempts at distance learning have been made for nearly 40 years. The COVID-19 pandemic will likely continue for a while, and the pros of conducting remote classes, such as reducing long commuting times and being able to take control of one's rhythm of life, have been widely understood. On the other hand, some classes can only be conducted face-to-face, such as practicums and experiments, so accommodations would need to be made.

Soon, drones will be carrying our luggage, and self-driving cars will be able to take us where we want to go after typing it in. The development of AI text generators that summarize events into easy-to-understand sentences just by coming up with the 5W1H may render most keyboards and writers unnecessary, and AI glasses will allow us to send and receive messages. As the new era is about to begin, it might not be the best idea to go back to pre-COVID schooling. In the future to come, we should consider developing flexible and diverse classes by actively utilizing new tools, rather than the standardized classes of the past.

In contrast, there will be a number of students who cannot keep up with the new trends and might feel highly anxious, stressed, and lonely, and a method to appropriately respond to each student will a future issue.

\section{Acknowledgements}

I would like to thank the following people for their cooperation in the questionnaire survey. Akira Ogiwara (Mie University), Harumi Hashimoto (Setsunan University), Sakiko Kasuya (Gifu Shotoku Gakuen University Junior College), Mikiko Nakata (Hiroshima Jogakuin University), Tomiya Yamazumi (Nagoya University of Economics).

\section{References}

Akcil, U., \& Bastas, M. (2021). Examination of university students' attitudes towards e-learning during the COVID-19 pandemic process and the relationship of digital citizenship. Contemporary Educational Technology, 13(1). https://doi.org/10.30935/CEDTECH/9341

Al-Kumaim, N. H., Alhazmi, A. K., Mohammed, F., Gazem, N. A., Shabbir, M. S., \& Fazea, Y. (2021). Exploring the impact of the covid-19 pandemic on university students' learning life: An integrated conceptual motivational model for sustainable and healthy online learning. Sustainability (Switzerland), 13(5). https://doi.org/10.3390/su13052546

Amir, L. R., Tanti, I., Maharani, D. A., Wimardhani, Y. S., Julia, V., Sulijaya, B., \& Puspitawati, R. (2020). Student perspective of classroom and distance learning during COVID-19 pandemic in the undergraduate dental study program Universitas Indonesia. BMC Medical Education, 20(1). https://doi.org/10.1186/s12909-020-02312-0

Biswas, B., Roy, S. K., \& Roy, F. (2020). Students Perception of Mobile Learning during COVID-19 in Bangladesh: University Student Perspective. Aquademia, 4(2). https://doi.org/10.29333/aquademia/8443

Ilieva, G., Yankova, T., Klisarova-Belcheva, S., \& Ivanova, S. (2021). Effects of covid-19 pandemic on university students' learning. Information (Switzerland), 12(4). https://doi.org/10.3390/info12040163

Kanoh, H. (2020). Possibility of Online Classes in Higher Education at Post-COVID-19-Froma Survey on the 
Internet Environment and ICT Equipment Ownership forStudents' Online Classes. Proceedings of the Annual Meeting of Japan Society for Science Education, (44), 521-524. https://doi.org/10.14935/jssep.44.0_521

Ministry of Education, Culture, Sports, Science and Technology. (2020). Implementation Status of Classes at Universities, etc. Based on the Status of the Novel Coronavirus. Retrieved from https://www.mext.go.jp/content/20200717-mxt_kouhou01-000004520_2.pdf

\section{Copyrights}

Copyright for this article is retained by the author(s), with first publication rights granted to the journal.

This is an open-access article distributed under the terms and conditions of the Creative Commons Attribution license (http://creativecommons.org/licenses/by/4.0/). 